was a salutary reminder that, in spite of the mass of information imparted during the week, our knowledge of the relationship between structure and function is still fragmentary-apparently two currently irreconcilable views are held on the mechanism of amceboid movement.

The arrangements made by Prof. $O$. Lindberg and his colleagues in the Wenner-Grens Institute for this symposium were superb, and, thanks to their hard work and genius for organization, everything moved smoothly. Furthermore, the Wenner-Gren Foundation generously supported the symposium financially, and without its aid its existence would have been highly problematical. As could well be imagined, remembering the nationality of our hosts, the social side of the symposium was not neglected and highlights included a banquet in Skansen and a visit to a performance of Pergolesi's "The Music Master" at the famous seventeenth-century Drottlingholm Theatre. A specially delightful feature was that all foreign delegates spent at least one evening in a Swedish home.

The International Union of Biochemistry and the International Union of Biological Sciences are truly grateful to their Swedish hosts for arranging the first joint symposium, and hope that this Stockholm symposium will be the forerunner of similar international symposia based on fruitful co-operation between biochemists and biologists from all nations. It is hoped to publish the proceedings of the symposium in book form in the near future.

T. W. GoodwrN

\title{
POWDERS IN INDUSTRY
}

GIR ALEXANDER FLECK, the president of the $S$ Society of Chemical Industry, in opening the first symposium of the Surface Activity Group of the Society of Chemical Industry held during September 29-30, commented on the many imperfectly understood problems of physics and physical chemistry relating to industrial applications of powders, and referred to the largely empirical nature of many oldestablished manufacturing processes involving powders. "In recent years, however", he said, "application of the growing body of knowledge on the surface properties of powders has led to striking improvements in both processes and products and will undoubtedly load to further developments, including the foundation of new industries".

In the words of Dr. M. G. Fleming, chairman of the organizing committee, the subject of powders was chosen for the symposium because so many industries make or use powders either as raw materials, intermediates or final products, many manufacturers being unaware of developments in otherwise unrelated industries which could assist them. The programme, he said, was planned to "sketch in the background and define the fundamental terms ; next examine the particular requirements and problems of a diverse group of industries, and, finally, correlate these specialized applications, underlining their contiguity and exposing the shortcomings in our basic knowledge of the subject".

A laudable aim, but the event left the impression of unevenness and there were marked swings in the discussion from academic argument concerning, for example, the meaning of surface tension, to some severely practical details of powder processing. This was perhaps the inevitable result of covering so wide a field, theoretical and practical, in a relatively short time, but there was great value in bringing together so much material, the sequential grouping of which proved admirable.

Thirty-one authors contributed in the four sections, which covered "Principles of Production", "Properties of Powders", "Properties of Powders utilized in Industrial Fields", and "Principles of Application and Problems for the Future". There were seven sessions, each with its own chairman and an introducer, who presented the papers as a group on behalf of the authors.
The papers of the first two sections concerned powder production by milling and by controlled precipitation, and the recovery and processing of natural powders; the surface energy of solids, adsorptive properties of powders, adhesion between particles, particle size, shape and surface area, and the electrical and flow-properties of powders. These together provided an excellent general background against which to study papers in the industrial section covering pigments and fillers in paints, printing inks, rubber and plastics (including a paper on whiting); powders as used in building cements, ceramics, bituminous road materials, cosmetics, detergents, pharmaceuticals, pesticides, paper, drilling fluids, and explosives; and problems of mineral dressing, soil mechanics, powder metallurgy, and coal and smokeless fuel production.

The papers revealed extensive basic research, much of it in relation to particular practical problems, and there was much evidence of considerable skill in process manipulation based on experience and technical appraisal of the products. In a brief report it is, however, impossible to give details of the numerous problems in powder production, manufacture and use, calling for further attention, or on which more fundamental knowledge would appear to be needed.

On the production side there were many references to the inefficiency of powder handling machines, particularly grinding mills (better understanding of energy relationships could lead to new methods of grinding), and to the unknowns in present methods of powder drying and powder size classification processes.

From the papers covering numerous industrial uses it was clear that while many of the outstanding problems are specific to particular industries, work in one field is not always being fully utilized in others. On the other hand, techniques of study successful in one industrial context can be unsuited to different materials and applications. For example, methods of particle-size determination adequate for size-ranges down to, say, one micron, giving useful information for particular applications, may be quite unsuitable for the much smaller particles sometimes involved in other types of product.

There is also the problem of how to measure effoctive or operative particle sizes, in particular 
environments, for while lnowledge of the geomotry of individual primary particles is valuable, frequently the operative unit is an agglomerate, flocculate or cluster of particles. Often information about what is happening to the constituent particles in an industrial product has to be deduced from the rheological, mechanical or other properties of that product, thero being an inadequacy of methods for directly observing the behaviour of particles within the mass.

In many industrial applications much more information is required about the interplay of particle and particle; about the bohaviour of particles distributed in gas or liquid in various concentrations in relation to the behaviour of single particles in the samo environments; also about the nature of the bond botween such particles and the surrounding mediurn, not only in the static product, but also during the various processes involved in its application or use and subsequent life.

What is the present state of basic knowledge about powders ? Here the conference was greatly assisted by the surveys made in the final section, with their collected information on well-established physico. chemical principles, and on the forces known to operate in dry or wet powders. Careful consideration of such information in relation to particular systoms could, it was suggested, indicate possiblo means of controlling the mochanical behaviour of powders or suspensions.
There woro calls for more information on the fundamentals of powder formation, and of the flow properties, internal packing, etc., of powders ; also on the molecular origin of electrostatic charges, adhesion between particles, and the cohesion of the mass. Thero were indications of the kinds of basic work needed to improve understanding of the factors affecting dispersion and flocculation of particles in solid/liquid systems, involving the inherent surface chemistry of solids, adsorption, chemisorption, etc., and the fine-structure of particles relative to methods (for example, adsorption methods) of measuring 'surface area'. Recent rapid advances in microscopy, and in olectron microscopy in particular, were noted, with the suggestion that microscopists should seek still further to improve their techniques.

To summarize, the symposium brought together a mass of matorial, fundamental and practical. It revealcd the 'zones of ignorance' and the kind of investigations required for' further advance. Individual powder-using industries can be expected to continue the search for new basic knowledge pertinont to the solution of their own problems, but their task would be facilitated by more extensive fundamental studies at the universities and in central research organizations. The field having beon so well surveyod, it would be woll for the participants to meet again in two or three years time to examine progress.

S. H. BELL

\section{COMPOSITION OF MILK IN THE UNITED KINGDOM}

$\mathrm{U}$ NTIL quite recently the quality of milk has been judged mainly on its fat content, but in the past thirty years an increased understanding of the principles of nutrition has made it clear that the most important constituents of milk are not the fats but the proteins, minerals and water-soluble vitamins which are, of course, to be found in the non-fatty solids portion of the milk. Research in the past decade has indicated that sinee 1930 or so in England and Wales the content of solids-not-fat: in milk, and therefore the nutritive value of the milk, has tended to decline slightly but significantly. For many hords the solids-not-fat content of the bulked milk has been maintained well above the presumptive legal limit of 8.5 per cent, but for an undesirably high proportion of herds it has frequently been below it.

These facts led in 1958 to the appointment by the Minister of Agriculture, Fisheries and Food, the Minister of Health and the Secretary of Stato for Scotland of an interdepartmental committee under the chairmanship of Dr. J. W. Cook to consider the composition of milk and to recommend any legislative or other changes that might seem desirable. The Committee's report has now been published*. Various members of the Cormmittoo formed three panels, which considered modical and animal husbandry aspects, and the freezing-point (Hortvet) test, for detecting tho presence of added water in milk. The * Milk Composition in the Tinited Kingdom: Report of an Inter-
departmental Committee. Pp. ifi +92. (Cmand. 1147.) (London: $\mathbf{Y} . \mathbf{M}$. Stationcry Ofhce, 1960.) 5s. net. reports of all three panels are published with the main report.

The Committee points out that great progress has been made in past years in improving the hygienic quality of milk; its members rightly believe that similar progress should now be made in improving its nutritive quality. To that end they have put forward some twonty-three main recommendations. They suggest, among other things, that the presumptive minimum legal standard of $8 \cdot 5$ per cont for the solids-not-fat content of milk should be abolished and that price penalties should ultimately be imposed when milk contains $8 \cdot 4$ per cent and less. They recommend also that milk-recording associations should provide means for testing the milk of individual cows for solids-not-fat as well as for fat.

There will certainly be many problems to solve before all the main recommendations made in the report can bo implemented, and some breed societies and other bodies concerned will feel that the recommendations go much too far, while others will inevitably think that they do not go far enough. However that may bo, it is clear that the Committee has done a very thorough job and that the adoption of its recommendations should have the desired effect of arresting and even reversing any tondency thero may be for the nutritional quality of milk in the United Kingdom to decline. The roport contains a wealth of information on the subject of the composition of milk and will long remain a most valuable and reliable work of reference on that subject. 